\title{
IMPACTOS DAS ELEIÇÕES PRESIDENCIAIS NAS EMPRESAS FEDERAIS
}

IMPACTS OF PRESIDENTIAL ELECTIONS ON FEDERAL COMPANIES

Recebido em 03.08.2020 Aprovado em 03.12.2020

Avaliado pelo sistema double blind review

DOI: https://doi.org/10.12712/rpca.v14i4.44397

\section{Paulo Schmidt}

E-mail: pschmidt@ufrgs.br

Programa de Pós-Graduação em Controladoria e Contabilidade/Universidade Federal do Rio Grande do Sul Porto Alegre/Rio Grande do Sul, Brasil

https://orcid.org/0000-0002-7341-1316

\section{Marco Antonio dos Santos Martins}

E-mail: mmartins@ufrgs.br

Programa de Pós-Graduação em Controladoria e Contabilidade/Universidade Federal do Rio Grande do Sul Porto Alegre/Rio Grande do Sul, Brasil

https://orcid.org/0000-0001-9365-3980

\section{Gustavo Martins Quadrado}

E-mail: quadrado43@gmail.com

https://orcid.org/0000-0002-5000-8137

\section{Resumo}

Este estudo examinou os impactos do primeiro turno da eleição do Presidente Bolsonaro nas cotações das ações das estatais federais listadas na B3. A análise utilizou o método de Estudo de Eventos. Os documentos analisados apontam que os resultados são significantes, indicando que há diferenças relevantes entre o retorno normal e o anormal das ações analisadas. Portanto, demonstrou-se que as expectativas dos agentes econômicos em relação à influência dessas eleições são transferidas às cotações das ações dessas empresas no mercado de capitais. O estudo demonstrou que essa eleição gerou retornos anormais estatisticamente significante nos preços das ações das empresas estatais.

Palavras-chave: Eleições. Estudo de Eventos. Empresas Estatais Brasileiras.

\begin{abstract}
This study examined the impacts of the first round of the election of President Bolsonaro on the stock prices of the federal state companies listed on B3. The analysis used the Event Study method. The analyzed documents point out that the results measured are significant, indicating that there are relevant differences between the normal and abnormal returns of the stocks analyzed. Therefore, it was demonstrated that the expectations of economic agents in relation to the influence of these elections are transferred to the quotations of the shares of these companies in the capital market. The study demonstrated that this election generated statistically significant abnormal returns in the stock prices of the companies studied.
\end{abstract}

Keywords: Elections. Event Study. Brazilian State Companies. 


\section{Introdução}

Os agentes que atuam no mercado financeiro levam em consideração vários fatores para otimizar seu processo de tomada de decisão, dentre eles destaca-se o conhecimento das empresas e mercados, além de toda e qualquer nova informação que afete em quaisquer aspectos a antecipação feita por esses agentes em relação ao rumo do mercado. Desse modo, há a tendência de os investidores compreenderem de melhor maneira os riscos que seus investimentos estão expostos e sua capacidade de controlar esses riscos (Goes, 2015).

Estudo de Eventos é uma das ferramentas metodológicas que se pode utilizar para a mensuração desses impactos. Essa metodologia consiste na análise dos impactos ocorridos no mercado a partir de um evento específico, podendo ele ser interno ou externo às organizações, sendo analisado o impacto no preço da ação e seu retorno à normalidade (Bergmann, 2015).

Questões de política econômica e seu reflexo na atividade econômica e nas empresas são de interesse dos investidores, empresas, trabalhadores, pesquisadores e sociedade de forma geral, pois essas variáveis são capazes de afetar o sistema financeiro do país, tanto negativamente quanto positivamente, o que reverbera por todos os setores do país (Silva, Barbosa, \& Ribeiro, 2016). Consequentemente, eventos que possam representar uma alteração potencial mudança na estrutura do governo e/ou na formulação de políticas públicas tendem a afetar a vida empresarial e seus planos de desenvolvimento e crescimento e por consequência o processo de geração de lucros e de precificação das empresas.

Dentro desse contexto, o processo eleitoral que possa representar mudanças bruscas na linha de condução das políticas econômica, bem como a orientação estratégica do governo, tende a afetar o processo de precificação dos ativos.

Além disso, no cenário brasileiro as empresas estatais federais tem um preso importante no mercado de capitais, com cinco empresas estatais federais integrando o IBOVESPA em 31/dez/2018, com uma participação de $14,5 \%$ do IBOVESPA, ou 18,8\% do valor de mercado do IBOVESPA (economatica.com.br), demonstrando a relevância das empresas estatais federais na bolsa de valores do Brasil, que atuam na produção de insumos básicos e serviços públicos, como a Petrobras, Banco do Brasil, Banco do Brasil Seguridade, Eletrobras, Petrobrás BR Distribuidora, que devido a forma como foi estruturado o plano das estatais brasileiras representam cada setor da economia e demonstram claramente os reflexos das decisões políticas no meio corporativo (Silva, Barbosa \& Ribeiro, 2016; Santos, 2017).

Considerando esses aspectos, esse estudo busca responder o seguinte problema de pesquisa: quais os impactos do resultado do primeiro turno das eleições do Presidente Jair Messias Bolsonaro nas empresas estatais federais listadas na B3?

Neste sentido, esse estudo objetiva identificar os impactos gerados pelo resultado do primeiro turno da eleição do Presidente Jair Messias Bolsonaro nas cotações das ações das empresas estatais federais brasileiras de capital aberto listadas na B3. Há diversos estudos que visaram compreender como as modificações nas informações presentes no mercado em relação à política de um país afetam o preço das ações no mercado de capitais, como os estudos de Camargo e Barbosa (2003), Vieira e Procianoy (2003), Bastos, Rosa e Pimenta (2016), Santos (2017) e Prechter Júnior et al. (2012). Porém, no Brasil não foram identificados estudos que discutem a relação entre a influência do resultado das eleições do país e a volatilidade dos preços das ações das empresas públicas na bolsa de valores. Dessa maneira, é configurada a relevância e motivação do presente estudo em inserir o tema na discussão teórica da análise de eventos na academia. 


\section{Referencial teórico}

Esta seção apresenta a fundamentação teórica do presente estudo, sendo subdividida em fundamento teórico dos estudos de eventos, o evento das eleições e suas implicações e correlações dentro economia brasileira, e, por fim, reproduzidos os estudos relacionados ao tema.

\section{Estudos de eventos}

A relação inerente dos resultados de determinado evento com impactos na precificação das ações de uma empresa é evidenciada pelo estudo de evento. Além disso, aponta a reação do mercado quanto ao evento e a consequência que o mesmo pode ter no preço da ação. Dessa forma, tem-se que o método objetiva demonstrar em que nível o preço das ações está sendo impactado por um evento (Fama, 1969; Getz \& Page, 2016).

Acerca do evento, ele pode ser causado por diferentes agentes em seus ambientes. Por exemplo, no ambiente interno da empresa, temos eventos como: nova política de distribuição de lucros, extinção de linhas de negócio, mudança em estruturas financeiras; no caso do ambiente externo tem-se como exemplo: avanços tecnológicos, associação da empresa em casos de corrupção, ou as possíveis mudanças das pautas de interesse socioeconômico do local em que a empresa está instalada e que podem afetar diretamente as suas operações, que nesse caso trata-se das eleições (Mcwilliams \& Siegel, 1997).

A evolução desse método deu-se inicialmente por Dolley (1933), quando examinou o efeito nas ações em uma janela de 1921 a 1931, sendo sua base 95 anúncios em uma janela temporal variável para cada desdobramento. Em seguida foi aperfeiçoado e refinado nos estudos desenvolvidos por Myers e Bakay (1948), Baker, (1956, 1957, 1958), Ashley (1962) que removeram efeitos significativos dos preços e separaram eventos confundidos entre si. Posteriormente, podem-se dar destaques a estudos que impactaram diretamente na metodologia do estudo de evento, sendo eles: Ball e Brown (1968) e Fama et al. (1969) que trouxeram a metodologia que é usada hoje; por fim, Brown e Warner (1980, 1985), trazendo limitações em aplicações de dados com intervalos mensais e diários e Campbell, Lo e Mackinlay (1997) apresentando uma profunda análise sobre o estudo de evento, suas bases, limitações e problemas.

Isto posto, foram descritos por Campbell, Lo e Mackinlay (1997) sete procedimentos que compunham a estrutura para a realização de um estudo de evento:

1. Definição do evento: É nesta etapa que a partir do evento de interesse define-se a "data zero", sua data de ocorrência e a janela de evento que consiste no período no qual os preços das ações das companhias envolvidas serão examinados, devendo incorporar intervalos relevantes para a verificação das anormalidades nos preços. A janela é dividida em dois períodos: um anterior ao evento, objetivando a identificação de indícios do uso de informações privilegiadas; e um posterior que tem por objetivo fornecer evidências da velocidade e precisão do ajuste dos preços à nova informação liberada ao mercado (Camargos \& Barbosa, 2010);

2. Critérios de seleção: Consiste em elencar os critérios para a seleção das empresas a serem inseridas no estudo.

3. Determinação dos retornos normais e retornos anormais: O retorno normal é descrito como o retorno esperado em caso de o evento não ter ocorrido, ao passo que o retorno anormal é definido como o retorno real observado ex-post do valor da ação, menos o retorno normal durante o intervalo de tempo inserido na janela de evento. Isto posto, o retorno anormal de uma empresa $i$ em uma data de evento $t$ pode ser demonstrado pela seguinte fórmula: $A R_{i, t}=$ $R_{i, t}-E\left[R_{i t} \mid X_{t}\right]$, onde $\mathrm{AR}, \mathrm{R}$ e $\mathrm{E}[\mathrm{R}]$ são o retorno anormal, o retorno real e o retorno normal, respectivamente. 
4. Procedimento de estimativa: Posterior à definição do retorno anormal, deverá ser selecionado o modelo de performance do retorno normal. Para isso, é estabelecida uma janela de estimação para realizar o teste do procedimento ao aferir os parâmetros do modelo por meio de um subconjunto de dados. O ínterim utilizado para a janela compreende um período anterior e que não englobe o período analisado para o evento, prevenindo influências do evento no modelo de performance.

5. Procedimento de teste: Neste passo devem-se calcular os retornos anormais para as empresas selecionadas, visando verificar, através da determinação da técnica de agregação dos retornos anormais das empresas individuais, se o retorno anormal varia do normal, seguido da definição da hipótese nula, onde comumente $A$ Rit $=0$, por fim proceder para os testes estatísticos.

6. Resultados empíricos: Quando já feito o teste da hipótese e os estatísticos, verificando a anormalidade entre os retornos, são apresentados os resultados empíricos respeitando o desenho econométrico.

7. Interpretações e conclusões: Por último na estrutura de aplicação do modelo, está a fase de interpretações e conclusões, onde, além da análise dos resultados em sim, deve ser demonstrada a investigação dos principais resultados e conclusões obtidas, e que dessa investigação possa ter-se plenas condições em estruturar conclusões que levem a uma visão e compreensão clara dos modos pelos quais o evento criou efeitos, ou não, nos preços das ações.

Essas etapas delineiam os parâmetros necessários para a busca e análise de anormalidades, se existentes, nos retornos das ações das empresas estatais com negociações recorrentes na B3.

\section{Cálculo do retorno normal}

Existem diversas abordagens para o cálculo do retorno normal. Ainda assim, pode-se dividi-los em dois grupos majoritários: os modelos estatísticos e os modelos econômicos (Campbell, Lo \& Mackinlay, 1997; Kan, Robotti \& Shanken, 2013; Tonidandel, 2013; Pessanha et al., 2014; Demiguel, Dogales \& Uppal, 2014; Junior \& Carvalho, 2015; Pereira, Securato \& Sousa, 2016).

\section{Modelos estatísticos}

Os modelos estatísticos podem ser basicamente divididos em modelo de retorno médio constante, modelo de mercado e outros modelos estatísticos. Sua lógica de funcionamento parte de um pressuposto e certa suposição onde se pressupõe que o retorno dos ativos é, além de normais e multivariados, distribuídos identicamente e independentemente ao longo do tempo. E supõe-se que o comportamento do retorno dos ativos não é correlacionado de forma dependente a argumentos econômicos. É devido ao destaque em relação ao modelo de retorno médio constante que, apesar de ser o mais simples, constantemente disponibiliza resultados similares dos modelos mais sofisticados (Brown \& Warner, 1980, 1985). O modelo em questão pode ser representado conforme Brown e Warner (1980) pela seguinte equação:

$$
R_{i t}={ }_{i}+\sum i t ; E\left[\sum i t\right]=0 ; \operatorname{Var}\left[\sum i t\right]=\int 2
$$

Onde: $R_{i, t}$ : retorno da ação i no período t;

i: retorno médio do ativo

i; it: termo de distúrbio. 
Já o modelo de mercado parte da relação entre o retorno do portfólio de mercado, no estudo representado pelo IBOVESPA, com o retorno de uma ação qualquer (Polinsky \& Shavell, 2007). A especificação linear do modelo, além de necessitar que os valores que integram o portfólio mantenhamse constantes, supõe uma normalidade uniforme nos retornos dos ativos. Constata-se que as variações no portfólio têm pequeno efeito nos trabalhos empíricos, uma vez que suas variações, conforme o tempo, são reduzidas o suficiente para isso. Conforme Campbell, Lo e Mackinlay (1997), tal modelo foi formado para que pudesse ser aplicado a qualquer ação e é representado pela equação a seguir:

$$
R_{i t}=a_{i}+b_{i} R_{m t}+\sum i t ; E\left[\sum i t\right]=0 \operatorname{Var}\left[\sum i t\right]=\int 2
$$

Onde: $R_{i, t}$ : retorno da ação i no período t;

$a_{i} b_{i}$ : parâmetros do modelo de mercado;

$R_{m, t}$ : retorno do portfólio de mercado;

$\sum$ it: termo de distúrbio.

Para Campbell, Lo e Mackinlay (1997), há diversos outros modelos que se propõem a definir e calcular o retorno normal, tendo como exemplo o modelo de fatores, que, ao apresentar uma maior explicação do retorno normal, dispõe do benefício de diminuir a variância do retorno anormal, podendo ser divido em modelo de um fator, comumente chamado de modelo de mercado, e modelo de multifatores, que adiciona índices das indústrias que vão além do mercado, citando caso análogo à apresentação dos estudos de Sharpe (1970) e Sharpe, Alexander e Bailey (1995). Estes trazem o modelo de índices baseado na classificação da indústria. Apesar disso, para estudos de eventos, o ganho, ao aplicar modelos multifatoriais, é tipicamente significante quando as empresas analisadas têm uma característica em comum, como a participação do mesmo grupo de capitalização de mercado; caso contrário, o poder explicativo marginal dos fatores adicionais é baixo, limitando o ganho na diminuição da variância do retorno anormal.

\section{Modelos econômicos}

Os modelos econômicos utilizados para a realização do cálculo do retorno normal fornecem um modelo mais contraído de retorno normal. Isso se deve à busca em restringir os parâmetros que regem os modelos estatísticos. Segundo Zabarankin e Uryasev (2014), o modelo econômico dado como um dos fundamentais e com conceitos de grande influência nas finanças modernas é o CAPM (Capital Asset Pricing Model). Também há extensões do cálculo CAMP, os quais são comumente utilizados para realizar a tentativa de superar as suas suposições irrealistas. Esse é o caso do APT (Arbitrage Pricing Theory) (Elbannan, 2015).

O CAPM foi primeiramente apresentado nos estudos de Sharpe (1964), Lintner (1965) e Mossin (1966). Eles basearam-se no estudo de Markowitz (1959) que arquitetou o "modelo de variância média", decorrente do “trade off” entre risco e retorno, onde o risco é definido como variável. Dessa forma, ao desenvolverem o modelo de Markowitz, construíram uma teoria de equilíbrio que estabelece uma função linear da covariância do retorno de um determinado ativo com o retorno de um portfólio de mercado para a determinação do retorno esperado desse ativo. Essa relação é dada por beta, delineado, justamente, a partir da razão da covariância dos retornos do ativo e do portfólio pela variância deste.

Ao passo que o APT, desenvolvido por Ross (1976), evidenciou uma teoria de precificação de ativos em que a covariância com fatores múltiplos do retorno de determinado ativo define o retorno esperado do mesmo ativo, ou seja, todo equilíbrio será a relação linear entre o retorno esperado dos ativos e a expressividade das respostas do retorno sobre o fator comum. Dessa forma, os betas são proporcionais às covariâncias dos retornos com os fatores. Porém, para isso, faz-se necessária a ausência de oportunidades de arbitragem assintótica. 


\section{Interações do governo brasileiro na economia}

As eleições presidenciais criam grandes expectativas não só na população do próprio país, mas também de todos os mercados em que ele está envolvido. Isso decorre do fato que o representante escolhido pela população, ao assumir o cargo da presidência, pode influenciar a economia por intermédio de ações governamentais que se utilizam de instrumentos econômicos com o intuito de atingir objetivos macroeconômicos determinados. Estas ações são definidas como políticas econômicas (Tinbergen, 1986).

Para Martins (2007), a atividade e estabilidade econômica do país podem ser impactadas de forma significativa por diversos fatores, podendo ocasionar repercussões como crises políticas e econômicas, aumento da inflação, aumento na taxa de juros, entre outros. Os quatro instrumentos que o governo manuseia para conduzir a economia, conforme Assaf Neto (2014), são: política monetária, fiscal, cambial e a de rendas.

A política monetária pode ser definida como a atualização de instrumentos de controle da oferta de moeda e taxa de juros com o objetivo de controlar a liquidez do sistema econômico e atingir os planos da política econômica global do governo em exercício (Lopes \& Rosetti, 1998). Segundo Oliveira e Pacheco (2006), a política monetária tem a capacidade de influenciar as decisões dos consumidores sobre poupar ou consumir, decisões de investimentos, taxa de desemprego, e especialmente a inflação onde é essencial na sua estabilização, podendo ser classificada como a que mais afeta a economia do país. Além disso, ela contribui para que a economia do país desenvolva-se e cria condições para que preços estabilizem-se, PIB cresça e a criação de um ambiente com pleno emprego (Martins, 2007).

No Brasil, o órgão responsável pelo planejamento e cumprimento da política monetária é o Banco Central (BACEN). De acordo com Mishkin, Mishkin e Mishkin (2000), para alcançar os objetivos econômicos do governo, o BACEN utiliza três instrumentos básicos: operações de mercado aberto (open market), política de desconto (redesconto) e exigências de reservas (depósito compulsório).

No tocante aos outros elementos da política econômica, a política fiscal envolve o delineamento e execução da carga tributária sobre os agentes econômicos. Com base nesses tributos arrecadados, há a definição dos gastos do governo por meio do orçamento. Portanto, essa política pode ser definida, em acordo com Fortuna (2010), como a política de receitas e despesas do governo. exemplo, os salários, lucros e dividendos. Após ficar explicitado como o Governo interveem na economia de modo geral, pode dar-se foco à interação entre o estado e as empresas estatais. Tem-se em vista que, assim como em outros países da América Latina, no Brasil, por conta do afluxo de teorias estruturalistas cepalinas, o Estado assume perfil intervencionista, tendo a visão de promover a industrialização do país para superar o atraso no seu desenvolvimento econômico (Bresser-Pereira \& Gala, 2010).

O Governo ao assumir o papel de indutor do processo industrial, por meio das estatais, articula e financia blocos de investimento específicos para o manejo da estrutura da economia brasileira. Para mais, podem ser atribuídos às estatais os propósitos de: prover infraestrutura básica para o desenvolvimento econômico do país; fornecer bens e serviços que permitam que o Estado usufrua de vantagens das quais a iniciativa privada beneficia-se; estimular negócios privados significantes para o desenvolvimento do país; e obter vantagens derivadas do monopólio econômico (Dutra, 1991; Gobetti, 2009).

Entretanto, foram utilizadas como instrumento da política macroeconômica para a captação de recursos no exterior, independentemente da existência da necessidade de crédito, com objetivo de contribuir para equilíbrio da balança de pagamentos do país, do mesmo modo que foram sujeitas a políticas de reajustamento de preços praticados por elas, prejudicando sua capacidade de autofinanciamento e seu desempenho de forma geral em troca da moderação da inflação no curto prazo, isso deu início a um ciclo vicioso que tornou diversas estatais em pesos orçamentários (Ribeiro, Alves \& Chede, 2009). 
Com o passar dos anos, houve oscilações entre as estatais estarem no espectro de vilãs da crise fiscal ou de contribuintes significativas para o superávit primário do setor público e para as receitas tributárias. Todavia, desde 2013 vem figurando negativamente devido às críticas na gestão e no uso político das empresas estatais após denúncias de corrupção que vieram à tona na operação "Lava Jato" na Petrobrás, a maior empresa estatal brasileira.

Segundo Tácito (2005), pode-se observar que as empresas estatais têm formato semelhante às privadas; porém, sua essência é pública. Dessa maneira, o propósito do lucro é substituído por objetivos de utilidade pública. Logo o motivo impulsionador para instituição das estatais pelo Estado segue um caminho alternativo do característico da área privada ao adentrar em um empreendimento, dado que a conduta estatal apenas pode ser validada ao promover os anseios públicos, independente da sua unidade como organização empresarial guarnecida com personalidade jurídica de direito privado. Nessa perspectiva, os governos democráticos utilizam as políticas públicas para traduzir seus objetivos em programas designados a implementá-los. Quanto às formas de políticas públicas, dividem-se em quatro grupos: distributivas, redistributivas, regulatórias e constitutivas (Souza, 2007).

Em breve síntese, as políticas distributivas geram benefícios para alguns grupos sociais e o custo é suportado de modo pulverizado por toda população; as políticas redistributivas, em contrapartida, geram benefícios a certos grupos sociais e seus custos são sustentados por outros grupos sociais; as políticas regulatórias constituem padrões de condutas, produtos ou serviços; as políticas constitutivas determinam, além da própria elaboração de políticas públicas, competências e regras próprias a disputas políticas (Sechi, 2012).

Pelo fato das estatais não integrarem a Federação como pessoas políticas, e ainda não estão revestidas de parte dos poderes de soberania do estatal, elas não possuem poder normativo; portanto, não há o uso de políticas constitutivas ou regulatórias, mesmo que Pinto Júnior (2010) não exclui a possibilidade de que as empresas estatais assumam uma postura regulatória quando agem como contraponto do poder econômico privado, influenciando os agentes econômicos a atuarem em caráter social.

É possível observar que o exercício das empresas estatais necessariamente passa pela esfera política, pois compreende a toma de decisão e posterior repasse em ações corretivas sobre o andamento das atividades da empresa em forma de alinhar com as diretrizes políticas escolhidas. À vista disso, as decisões tomadas pelo Governo que tangem a economia criam grandes expectativas nos agentes do mercado, especialmente investidores, sendo que em períodos eleitorais essa criação de expectativas tende a intensificar-se (Silva, Barbosa \& ribeiro, 2017; Martins, 2014).

\section{As eleições presidenciais e o mercado de capitais}

As eleições presidências costumeiramente despertam diversas expectativas, não só na população, mas em todos os agentes econômicos, em virtude das alterações nos cenários internos e externos que podem ser ocasionadas pelo sucessor presidencial. Isso ocorre, pois, as decisões do Governo são interpretadas e analisadas de maneira a projetar o momento mais propício para realizar ações como o de consumo, investimento e poupança (Martins, 2007).

De maneira similar os representantes do governo em posse da gestão tendem a ponderar sobre as demonstrações de expectativas, possíveis reações e necessidade do mercado, em vista de desenvolver políticas econômicas e públicas que tenham foco em trazer um balanço equitativo em relação ao desenvolvimento social e econômico da sociedade brasileira.

À vista disso, o mercado de capitais é um elemento essencial para o crescimento da economia, dado que a atividade econômica nas economias modernas está estritamente ligada à mediação entre os agentes poupadores de recursos (superavitários) e os tomadores de recursos (deficitários). Pinheiro (2009) destaca que essa condução dos recursos é um dos importantes objetivos dos mercados financeiros. Ambos os 
agentes são essencialmente responsáveis por parte da produtividade e crescimento econômico em razão do direcionamento dos recursos poupados aos agentes tomadores, os quais usufruem das oportunidades de investimento para assim poder financiar as atividades das suas respectivas empresas (NEVES, 2007).

A ligação econômica funcional presente entre esses dois importantes componentes direcionadores de uma grande fatia da economia diz respeito a uma fatia de tamanho equivalente de expectativas vinda dos investidores. Uma parcela dos reflexos dessas interações pode ser observada diretamente nos aspectos da bolsa de valores, como volume de negociações, índice Ibovespa, etc. Em 2014, o mercado de capitais brasileiro bateu recorde de negociações, o qual ocorreu durante as eleições presidenciais. Para mais, especificamente, no $1^{\circ}$ turno das eleições do período, o índice Ibovespa subiu 8\%. Até mesmo as ações da companhia Petrobras envolvidas em denúncias de corrupção tiveram altas de até 17\% (Exame, 2014). Seguindo o mesmo caminho, em 2018, a bolsa atinge o recorde histórico de negócios realizados nos segmentos BM\&F e Bovespa juntos, somando 4.734.609, no dia posterior ao do resultado do primeiro turno das eleições. O índice Ibovespa avança 4,57\% a 86.083 pontos (Folha de São Paulo, 2018a; B3, 2018).

A respeito das eleições brasileiras, é possível inferir que as expectativas dos eleitores quanto ao próximo presidente a ser eleito são expressas em sua grande maioria em seus votos no primeiro turno. Isso é devido pelo fato que, desde a redemocratização do Brasil, em 1989, o candidato a vencer o primeiro turno das eleições é, por consequência, o vencedor do segundo turno, sendo presidente da federação (Folha de São Paulo, 2018b). Além do mais, desde o período citado, os eleitores tomam como fator central de escolha em cenários de mudança presidencial a sua avaliação da política macroeconômica e dos efeitos nas decisões da política econômica no cenário nacional, conforme Peixoto e Rennó (2011). Isto se refere ao uso do conhecimento da economia por parte do indivíduo para sua decisão de voto.

Duch e Stevenson (2008) basearam-se em pontos da teoria do voto econômico e expuseram que esse conhecimento em sua grande maioria é advindo de informações com origem na experiência pessoal em relação à economia, a qual é replicada para julgar a competência dos governos. Portanto, podemos ver as diversas influências de todos os agentes entre si através de suas expectativas, posicionamentos e decisões.

\section{Estudos relacionados}

Diversos estudos debruçaram-se sobre o tema da análise de variáveis do mercado de capitais brasileiro com o propósito de averiguar se a hipótese de influência de determinados eventos nos preços das ações é afirmativa, correspondendo a uma reação eficiente do mercado e um impacto significativo dos retornos das ações, podendo alguns desses estudos serem elencados, como os de Camargos e Barbosa (2010),Vieira e Procianoy (2003), Bastos, Rosa e Pimenta (2016), Santos (2017) e Prechter Júnior et al. (2012).

Camargos e Barbosa (2010) investigaram, através de um estudo de eventos, se há presença de eficiência informacional semiforte no mercado de capitais brasileiro pós-Plano Real quando da divulgação de fusões e aquisições de empresas com ações na B3. O resultado apresentado na pesquisa demonstra que, pelo espectro da eficiência informacional considerando a sua forma semiforte, o mercado de capitais brasileiro não se comportou de maneira eficiente.

Vieira e Procianoy (2003) pesquisaram, mediante o uso do estudo de eventos, a reação de mercados considerados fracos ou em desenvolvimento na América Latina, como Brasil, Argentina, Chile, Colômbia e México, em relação à emissão e distribuição de ações por parte da empresa para seus acionistas, chamada de bonificação. Os resultados prevalecentes indicam que há retornos positivos e significantes no entorno do primeiro dia de negociações ex-evento. Porém, a diferença entre os países é pequena e a sobre-reação na data de realização foi identificada tanto nesse mercado quanto em um mercado expressivo como o dos Estados Unidos. Ademais, pode-se observar a ineficiência destes mercados pelo fato que, a partir de uma informação publicamente disponível, os investidores alcançaram retornos acima dos esperados. 
Bastos, Rosa e Pimenta (2016) analisaram como o evento da deflagração da operação "Lava-Jato" impactou os retornos das ações, ordinárias e preferenciais da Petrobrás, também inserida no cenário da crise internacional do petróleo. Verificou-se que o anúncio da operação Lava-Jato acometeu em retornos anormais nas ações ordinárias, obtendo reação positiva com 5\% de significância. Em contrapartida, os referentes às preferenciais não obtiveram reação. Não obstante, observa-se uniformidade dos comportamentos de ambas as ações diante deste evento ao utilizar retornos anormais acumulados.

Santos (2017) verificou em sua tese que foram produzidos efeitos no comportamento do preço das ações das maiores instituições financeiras no Brasil com capital aberto na BOVESPA, causados pelas eleições presidenciais ocorridas em 2006, 2010 e 2014 e o processo de impeachment, em 2016. A pesquisa mostrou que, dentro da janela de evento, os ativos dos bancos selecionados apresentaram retornos anormais significativos. Porém, algumas situações podem não ser explicadas pelo próprio evento preferido. De qualquer maneira, formam evidente anormalidade no modelo. Além disso, evidenciou a incapacidade do mercado brasileiro de incorporação das novas informações de forma imediata. Em outras palavras, apresentou um atraso do retorno ao seu ponto de equilíbrio. Por fim, foi praticável a observação que o maior impacto no preço de suas ações nos eventos ocorreu na instituição financeira de economia mista (controlada parcialmente pela União), seguida das empresas de capital privado.

Além dos estudos brasileiros citados acima, vale ressaltar outros estudos internacionais que se propuseram a analisar as repercussões das eleições presidências na volatilidade dos preços das ações no mercado. Prechter Júnior et al. (2012), por exemplo, pesquisaram a relação entre as reeleições dos presidentes dos EUA, incluindo todas as eleições presidenciais desde 1824, e o desempenho do mercado de ações. Os resultados mostraram que o desempenho prévio do mercado de ações relaciona-se significativa e positivamente com o voto marginal dos candidatos nas propostas de reeleição dos presidentes dos EUA. Porém, não foram encontradas relações significativas entre a margem de votos e a inflação ou desemprego, e o PIB demonstra-se como um preditor significativo na regressão simples, mas é insignificante na regressão múltipla. Por fim, a pesquisa elucida que as hipóteses de voto econômico não explicam os resultados, pois estes são coerentes com a teoria do voto socioeconômico, onde o humor social é um regulador mais forte que as variáreis econômicas e os eleitores inconscientemente creditam o líder pelo seu humor.

\section{Procedimentos metodológicos}

A pesquisa caracteriza-se como positivista e, com base em seus objetivos, classifica-se como descritiva. Ao se classificar a pesquisa com base nos procedimentos técnicos utilizados, ela enquadra-se como documental. Quanto à abordagem, a pesquisa caracteriza-se como quantitativa.

As empresas selecionadas para integrar esse estudo quantitativo foram as estatais federais e suas respectivas ações listadas na B3, além de apresentadas na $9^{\circ}$ edição referente ao $4^{\circ}$ trimestre de 2018 do "Boletim das empresas estatais federais" elaborado pela SEST (Secretaria de Coordenação e Governança das Empresas Estatais) e divulgado pelo Ministério da Economia. Porém, apenas as empresas com ações de liquidez relevante foram selecionadas.

Diante dessa conjuntura, identificou-se a Petrobras, a Eletrobras, o Banco do Brasil. As outras empresas estatais federais que apresentam menor liquidez e, por consequência, não compuseram a seleção do presente estudo foram a Eletrobras, Eletropar, o Banco da Amazônia, o Banco do Nordeste, e a Telebrás, além da BR Distribuidora e do BB Seguridade, por acompanharem diretamente as ações da Petrobras e Banco do Brasil.

Acerca do tratamento de dados, foi utilizado o método do estudo de eventos apresentado por Campbell, Lo e Mackinlay (1997) para a análise dos impactos do resultado das eleições presidenciais no valor das ações da Petrobras, a Eletrobrás e o Banco do Brasil; todas as empresas estatais federais listadas na BOVESPA. Deste modo, os procedimentos empregados para a condução do estudo contêm as seguintes 
etapas: Definição do Evento; Critério de Seleção; Retornos Normais e Anormais; Procedimento de Estimação; Procedimento de Teste e Resultados Empíricos.

A definição da janela do evento foi com a utilização de 3 dias antes e 3 depois, em que o evento do primeiro turno da eleição presidencial teve seu resultado dando o primeiro sinal do possível novo governo e suas estruturas que acabam por ter ligação direta às empresas analisadas. A janela do evento que compreende ao primeiro turno das eleições foi em 07/10/2018. Considerando que o dia em questão é um domingo, ou seja, final de semana, foi considerado como o dia do evento para a execução das análises o dia 08/10/2018, segunda-feira. Dessa maneira, a janela foi de 03 a 07/10/2018, tendo em conta que 06 e 07/10/2018 foi final de semana, e de 09 a 11/10/2018.

Através do software "The Economatica System", foram selecionadas as cotações históricas da Petrobras, a Eletrobrás e o Banco do Brasil. Em seguida, processaram-se seus retornos diários por meio do uso da fórmula logarítmica, pois, segundo Soares, Rostagno e Soares (2002), atende a um dos pressupostos dos testes estatísticos ao gerar retornos com distribuição que tende à normal. Uma vez que se utilizaram dados diários e o modelo de mercado, foram praticadas 120 observações dos retornos diários, tanto das empresas quanto do IBOVESPA. Identicamente às estatais, houve a determinação do retorno do IBOVESPA utilizando o mesmo software e mesmo período. Após verificar o retorno durante a janela do evento e o retorno normal estimado pelo modelo de mercado, incorreu-se para o cálculo da diferença entre ambos os retornos.

Posteriormente, houve a estimativa dos parâmetros de regressão linear das ações das estatais em relação ao mercado, isto é, realizar a seleção dos parâmetros para estimativa do CAPM, sendo os seguintes preferidos para o estudo:

1. Período de 120 dias anteriores à janela do evento para os retornos diários. Ao excluir a janela do evento da janela de estimação, tem-se por propósito a realização de uma precaução sobre a atuação do evento na estimação do parâmetro para a performance do modelo normal.

2. O Retorno de mercado consiste no retorno diário do índice IBOVESPA;

3. Risk free para o estudo traduz-se na taxa Selic diária;

4. Beta diário como consequência da regressão linear da ação em relação ao IBOVESPA.

5. Aplicação do Teste "T" e análise de variância (ANOVA), com o objetivo de apontar diferentes níveis de significância estatística dos retornos anormais aferidos na janela do evento.

Segundo Gaddis e Gaddis (1990), o teste “T” de Student, é o método paramétrico estatístico utilizado para aceitar ou declinar a $\mathrm{H} 0$, consiste basicamente em um teste paramétrico o qual desempenha a avaliação da média de dois grupos quando os dados assumem distribuição normal. Enquanto isso, segundo os autores, a ANOVA é um teste estatístico para determinar, simultaneamente, se há diferença significante entre os grupos analisados e através do "F de significância" apresentará se há a existência de significância dentre os grupos.

Prontamente à realização dos testes, há a verificação da hipótese nula (H0) ou hipótese alternativa (H1), onde a primeira define a inexistência de retornos anormais, estatisticamente significativos, na janela do evento; e a segunda define justamente a existência de retornos anormais estatisticamente significativos na janela do evento. Enfim, efetuou-se a apresentação dos resultados empíricos, suas interpretações e conclusões. 


\section{Análise dos dados}

Considerando que o Estudo de Eventos é um método utilizado para examinar o comportamento dos preços das ações em torno de eventos corporativos (KOTHARY e WARNER, 2006). O método está suportado no pressuposto de realizar uma comparação, na data do evento, do retorno real de um título com o seu retorno esperado, estimado a partir da modelagem do Capital Asset Princing Model (CAPM). A diferença, denominada de retorno anormal, tem por objetivo mensurar o impacto (ex-post) do evento sobre o valor da firma.

O retorno esperado foi obtido a partir dos parâmetros de regressão linear das ações das estatais em relação ao mercado, considerando a seleção dos parâmetros para estimativa do CAPM.

Considerando que as empresas estatais possuem o governo como acionista controlador, o presente estudo tem objetivo avaliar o impacto da eleição presidencial sobre os preços das ações das respectivas empresas.

Os resultados dos impactos do evento das eleições presidenciais no retorno das ações da Petrobras; Petrobras Distribuidora; Eletrobrás; Banco do Brasil e BB Seguridade serão apresentados a seguir.

Foram analisados os retornos das ações da Petrobras (PETR3 e PETR4); Eletrobrás (ELET3 e ELET6) e Banco do Brasil (BBAS3). As ações utilizadas no estudo foram as PN (código 4) devido a sua maior liquidez no mercado. Portanto, possuem um processo de formação de preços mais eficiente. Para analisar os impactos do evento da eleição presidencial de 2018 na precificação das ações citadas acima, foram identificados os retornos das ações negociadas na BOVESPA e o IBOVESPA na janela do evento.

No dia 07/10/2018 ocorreu a votação, apuração e posterior divulgação dos resultados do primeiro turno das eleições de 2018 para presidente da república. Por ser domingo, os impactos desse evento foram apresentados ao mercado no dia 08/10/2018, sendo esse dia o utilizado como data do evento analisado nesse estudo.

\section{Banco do brasil}

Os índices de fechamento, os retornos diários reais e os retornos normais e anormais do Banco do Brasil na janela do evento serão apresentados na Figura 1. Percebeu-se que o retorno diário real da IBOVESPA foi de 4,469008\%, do BB foi de 9,240624\%, o retorno normal do BB, estimativa através do CAPM, foi de $-7,726255 \%$, gerando um retorno anormal do BB de 16,966879\% (9,240624\% - $(7,726255 \%)$ $=16,966879 \%$ ).

Após a identificação desses resultados, efetuou-se um teste estatístico paramétrico de análise de variância, sendo seus resultados apresentados nas Tabelas 1, 2, 3 e 4. Ademais, o resultado da ANOVA está presente nas Tabelas 2 a 4. Com o intuito de testar o grau de significância examinando os dados por meio do teste "T" para a análise da variância (ANOVA), é possível averiguar que o p-valor ficou maior que o valor do Stat-t, revelando que os resultados são significantes com $95 \%$ de confiança; portanto, há hipótese alternativa de que há diferenças significativas entre o retorno normal e o retorno anormal é válida. 
Figura 1 - Resultados das janelas do evento da IBOVESPA e do Banco do Brasil

\begin{tabular}{|l|l|l|l|l|l|l|}
\hline \multicolumn{1}{|c|}{ Data } & \multicolumn{1}{|c|}{$\begin{array}{l}\text { Fechamento } \\
\text { IBOVESPA }\end{array}$} & $\begin{array}{c}\text { Retorno Diário } \\
\text { Real } \\
\text { IBOVESPA }\end{array}$ & $\begin{array}{c}\text { Fechamento } \\
\text { BBAS3 }\end{array}$ & $\begin{array}{l}\text { Retorno Diário } \\
\text { Real BBAS3 }\end{array}$ & $\begin{array}{c}\text { Retorno } \\
\text { Normal } \\
\text { BBAS3 }\end{array}$ & \multicolumn{1}{|c|}{$\begin{array}{c}\text { Retorno } \\
\text { Anormal } \\
\text { BBAS3 }\end{array}$} \\
\hline $03 / 10 / 2018$ & 83.273 & $2,014943 \%$ & 33,86 & $8,679924 \%$ & $-3,440081 \%$ & $12,120006 \%$ \\
\hline $04 / 10 / 2018$ & 82.953 & $-0,385728 \%$ & 34,69 & $2,420868 \%$ & $0,734646 \%$ & $1,686221 \%$ \\
\hline $05 / 10 / 2018$ & 82.322 & $-0,763934 \%$ & 35,30 & $1,749974 \%$ & $1,378322 \%$ & $0,371652 \%$ \\
\hline $08 / 10 / 2018$ & 86.084 & $4,469008 \%$ & 38,72 & $9,240624 \%$ & $-7,726255 \%$ & $16,966879 \%$ \\
\hline $09 / 10 / 2018$ & 86.088 & $0,004217 \%$ & 38,52 & $-0,511510 \%$ & $0,060398 \%$ & $-0,571908 \%$ \\
\hline $10 / 10 / 2018$ & 83.679 & $-2,837532 \%$ & 36,89 & $-4,322873 \%$ & $5,024737 \%$ & $-9,347611 \%$ \\
\hline $11 / 10 / 2018$ & 82.921 & $-0,910017 \%$ & 36,74 & $-0,402415 \%$ & $1,653252 \%$ & $-2,055667 \%$ \\
\hline
\end{tabular}

Fonte: elaborada a partir dos dados obtidos na pesquisa.

Tabela 1 - Resultados estatísticos da regressão da janela do evento

\begin{tabular}{lc}
\hline & Estatística de regressão \\
\hline R múltiplo & 0,815853259 \\
R-Quadrado & 0,66561654 \\
R-quadrado ajustado & 0,662782782 \\
Erro padrão & 0,024123435 \\
Observações & 120 \\
\hline
\end{tabular}

Fonte: autores

Tabela 2 - Resultados a Anova da janela do evento

\begin{tabular}{|c|c|c|c|c|c|}
\hline & GI & SQ & MQ & $\mathrm{F}$ & F de significação \\
\hline Regressão & 1 & 0,136690902 & 0,136690902 & 234,888268 & 7,62271E-30 \\
\hline Resíduo & 118 & 0,068668932 & 0,00058194 & & \\
\hline Total & 119 & 0,205359833 & & & \\
\hline
\end{tabular}

Fonte: autores

Tabela 3 - Resultados a Anova da janela do evento

\begin{tabular}{lllll}
\hline & \multicolumn{1}{c}{ Coeficientes } & Erro padrão & Stat-t & \multicolumn{1}{c}{ valor-P } \\
\hline Interseção & 0,000167228 & 0,002202317 & 0,075932562 & 0,93960134 \\
Variável X 1 & 1,620744871 & 0,105750881 & 15,32606499 & $7,62271 \mathrm{E}-30$ \\
\hline
\end{tabular}

Fonte: autores

Tabela 4 - Resultados a Anova da janela do evento

\begin{tabular}{lllll}
\hline & $95 \%$ inferiores & $95 \%$ superiores & Inferior $95,0 \%$ & Superior $95,0 \%$ \\
\hline Interseção & $-0,00419396$ & 0,004528415 & $-0,00419396$ & 0,004528415 \\
Variável X 1 & 1,411329336 & 1,830160405 & 1,411329336 & 1,830160405 \\
\hline
\end{tabular}

Fonte: autores

\section{Petrobras (petr3)}

Os resultados dos retornos e fechamentos diários reais, retornos normais e anormais da ação PETR3 da estatal Petrobras serão indicados na Figura 2, juntamente com os fechamentos diários reais e retorno diário real do IBOVESPA. Tendo em vista que é um único evento, o valor do retorno diário real do IBOVESPA mantém-se o mesmo. Com isso, pode-se seguir a observação sobre os retornos de cada 
ação. No presente caso, a PETR3 auferiu um retorno anormal de $16,203107 \%$, o qual foi composto pela comparação do retorno diário real $(9,066187 \%)$ com o retorno normal estimado $(-7,136920 \%)$.

Os dados resultantes da análise feita pelo teste "T" para a ANOVA demonstraram que o valor obtido para o p-valor de 0,637891497 ficou acima do 0,471869275 obtido pelo Stat t, apontando que a hipótese alternativa é verdadeira, o que significa que as diferenças entre o retorno normal da ação e o anormal tiveram diferenças consideradas significativas quanto à influência do evento na precificação da ação. Esses resultados do teste estatístico são apresentados nas Tabelas 5 a 8.

Figura 2 - Resultados das janelas do evento da IBOVESPA e da Petrobras (PETR3)

\begin{tabular}{|l|l|l|l|l|l|l|}
\hline \multicolumn{1}{|c|}{ Data } & \multicolumn{1}{|c|}{$\begin{array}{c}\text { Fechamento } \\
\text { IBOVESPA }\end{array}$} & $\begin{array}{c}\text { Retorno } \\
\text { Diário Real } \\
\text { IBOVESPA }\end{array}$ & $\begin{array}{c}\text { Fechamento } \\
\text { PETR3 }\end{array}$ & $\begin{array}{c}\text { Retorno } \\
\text { Diário Real } \\
\text { PETR3 }\end{array}$ & $\begin{array}{c}\text { Retorno } \\
\text { Normal } \\
\text { PETR3 }\end{array}$ & $\begin{array}{c}\text { Retorno } \\
\text { Anormal } \\
\text { PETR3 }\end{array}$ \\
\hline $03 / 10 / 2018$ & 83.273 & $2,014943 \%$ & 26,38 & $2,562772 \%$ & $-3,142414 \%$ & $5,705185 \%$ \\
\hline $04 / 10 / 2018$ & 82.953 & $-0,385728 \%$ & 26,66 & $1,051850 \%$ & $0,674954 \%$ & $0,376896 \%$ \\
\hline $05 / 10 / 2018$ & 82.322 & $-0,763934 \%$ & 26,56 & $-0,374392 \%$ & $1,267297 \%$ & $-1,641689 \%$ \\
\hline $08 / 10 / 2018$ & 86.084 & $4,469008 \%$ & 29,08 & $9,066187 \%$ & $-7,136920 \%$ & $16,203107 \%$ \\
\hline $09 / 10 / 2018$ & 86.088 & $0,004217 \%$ & 29,62 & $1,833045 \%$ & $0,057523 \%$ & $1,775522 \%$ \\
\hline $10 / 10 / 2018$ & 83.679 & $-2,837532 \%$ & 28,53 & $-3,770152 \%$ & $4,620185 \%$ & $-8,390337 \%$ \\
\hline $11 / 10 / 2018$ & 82.921 & $-0,910017 \%$ & 28,00 & $-1,868554 \%$ & $1,527701 \%$ & $-3,396255 \%$ \\
\hline
\end{tabular}

Fonte: elaborada a partir dos dados obtidos na pesquisa.

Tabela 5 - Resultados estatísticos da regressão da janela do evento

\begin{tabular}{lc}
\hline & Estatística de regressão \\
\hline R múltiplo & 0,619169683 \\
R-Quadrado & 0,383371097 \\
R-quadrado ajustado & 0,378145428 \\
Erro padrão & 0,029075182 \\
Observações & 120 \\
\hline
\end{tabular}

Fonte: autores

Tabela 6 - Resultados a Anova da janela do evento

\begin{tabular}{|c|c|c|c|c|c|}
\hline & GI & SQ & MQ & $\mathrm{F}$ & F de significação \\
\hline Regressão & 1 & 0,062018659 & 0,062018659 & 73,36307006 & $4,7757 \mathrm{E}-14$ \\
\hline Resíduo & 118 & 0,09975321 & 0,000845366 & & \\
\hline Total & 119 & 0,161771868 & & & \\
\hline
\end{tabular}

Fonte: autores

Tabela 7 - Resultados a Anova da janela do evento

\begin{tabular}{lllll}
\hline & \multicolumn{1}{c}{ Coeficientes } & \multicolumn{1}{c}{ Erro padrão } & \multicolumn{1}{c}{ Stat-t } & \multicolumn{1}{c}{ valor-P } \\
\hline Interseção & 0,001252488 & 0,002654311 & 0,471869275 & 0,637891497 \\
Variável X 1 & 1,584833969 & 0,185031224 & 8,56522446 & $4,7757 \mathrm{E}-14$ \\
\hline
\end{tabular}

Fonte: autores 
Tabela 8 - Resultados a Anova da janela do evento

\begin{tabular}{lllll}
\hline & \multicolumn{1}{c}{$\mathbf{9 5 \%}$ inferiores } & \multicolumn{1}{c}{$\mathbf{9 5 \%}$ superiores } & \multicolumn{1}{c}{ Inferior $\mathbf{9 5 , 0 \%}$} & Superior 95,0\% \\
\hline Interseção & $-0,004003771$ & 0,006508746 & $-0,004003771$ & 0,006508746 \\
Variável X 1 & 1,21842177 & 1,951246168 & 1,21842177 & 1,951246168 \\
\hline
\end{tabular}

Fonte: autores

\section{Petrobras (petr4)}

Os índices de fechamento e retornos diários reais do IBOVESPA, os índices de fechamento, os retornos diários reais e os retornos normais e anormais da Petrobras (PETR4) na janela do evento, serão apresentados na Figura 3. Conforme demonstrado na figura, o retorno normal estimado mediante uso do CAMP obteve o valor de 10,452544\%, que por fim resultou em um retorno anormal de 19,152044\% ao ser comparado com o valor do retorno diário real o qual teve valor de -8,699500\% $(10,452544 \%$ $(8,699500 \%)=19,152044 \%)$.

Em seguida, efetuou-se um teste estatístico paramétrico de análise de variância. Utilizou-se o teste "T" para a análise da variância (ANOVA) com a finalidade de testar o grau de significância dos dados. Através do teste, pode-se verificar que o valor obtido para o Statt é 0,511935755 , enquanto o valor do p-valor foi igual a 0,609652749. Dessa forma, é possível verificar que o p-valor ficou maior que o valor do Statt, indicando que os resultados são significantes com $95 \%$ de confiança, validando a hipótese alternativa de que há diferenças significativas entre o retorno normal e o retorno anormal. Esses resultados do teste estatístico são apresentados nas Tabelas 9 a 12.

Figura 3 - Resultados das janelas do evento da IBOVESPA e da Petrobras (PETR4)

\begin{tabular}{|l|l|l|l|l|l|l|}
\hline \multicolumn{1}{|c|}{ Data } & $\begin{array}{c}\text { Fechamento } \\
\text { IBOVESPA }\end{array}$ & $\begin{array}{c}\text { Retorno } \\
\text { Diário Real } \\
\text { IBOVESPA }\end{array}$ & $\begin{array}{c}\text { Fechamento } \\
\text { PETR4 }\end{array}$ & $\begin{array}{c}\text { Retorno } \\
\text { Diário Real } \\
\text { PETR4 }\end{array}$ & $\begin{array}{c}\text { Retorno } \\
\text { Normal } \\
\text { PETR4 }\end{array}$ & $\begin{array}{c}\text { Retorno } \\
\text { Anormal } \\
\text { PETR4 }\end{array}$ \\
\hline $03 / 10 / 2018$ & 83.273 & $2,014943 \%$ & 23,70 & $4,162798 \%$ & $-3,816893 \%$ & $7,979691 \%$ \\
\hline $04 / 10 / 2018$ & 82.953 & $-0,385728 \%$ & 23,92 & $0,962149 \%$ & $0,815997 \%$ & $0,146152 \%$ \\
\hline $05 / 10 / 2018$ & 82.322 & $-0,763934 \%$ & 23,86 & $-0,250104 \%$ & $1,545494 \%$ & $-1,795598 \%$ \\
\hline $08 / 10 / 2018$ & 86.084 & $4,469008 \%$ & 26,49 & $10,452544 \%$ & $-8,699500 \%$ & $19,152044 \%$ \\
\hline $09 / 10 / 2018$ & 86.088 & $0,004217 \%$ & 26,71 & $0,823666 \%$ & $0,064746 \%$ & $0,758921 \%$ \\
\hline $10 / 10 / 2018$ & 83.679 & $-2,837532 \%$ & 25,95 & $-2,913011 \%$ & $5,576436 \%$ & $-8,489447 \%$ \\
\hline $11 / 10 / 2018$ & 82.921 & $-0,910017 \%$ & 25,19 & $-2,960871 \%$ & $1,843015 \%$ & $-4,803885 \%$ \\
\hline
\end{tabular}

Fonte: elaborada a partir dos dados obtidos na pesquisa.

Tabela 9 - Resultados estatísticos da regressão da janela do evento

\begin{tabular}{lc}
\hline & Estatística de regressão \\
\hline R múltiplo & 0,696385811 \\
R-Quadrado & 0,484953198 \\
R-quadrado ajustado & 0,480588395 \\
Erro padrão & 0,028750172 \\
Observações & 120 \\
\hline
\end{tabular}

Fonte: autores 
Tabela 10 - Resultados a Anova da janela do evento

\begin{tabular}{|c|c|c|c|c|c|}
\hline & GI & SQ & MQ & $\mathrm{F}$ & F de significação \\
\hline Regressão & 1 & 0,091836652 & 0,091836652 & 111,1053931 & $1,04093 \mathrm{E}-18$ \\
\hline Resíduo & 118 & 0,097535544 & 0,000826572 & & \\
\hline Total & 119 & 0,189372196 & & & \\
\hline
\end{tabular}

Fonte: autores

Tabela 11 - Resultados a Anova da janela do evento

\begin{tabular}{lllll}
\hline & \multicolumn{1}{c}{ Coeficientes } & \multicolumn{1}{c}{ Erro padrão } & \multicolumn{1}{c}{ Stat-t } & \multicolumn{1}{c}{ valor-P } \\
\hline Interseção & 0,001343647 & 0,00262464 & 0,511935755 & 0,609652749 \\
Variável X 1 & 1,928548694 & 0,182962901 & 10,5406543 & $1,04093 \mathrm{E}-18$ \\
\hline
\end{tabular}

Fonte: autores

Tabela 12 - Resultados a Anova da janela do evento

\begin{tabular}{lllll}
\hline & \multicolumn{1}{c}{$95 \%$ inferiores } & \multicolumn{1}{c}{$95 \%$ superiores } & \multicolumn{1}{c}{ Inferior 95,0\% } & Superior 95,0\% \\
\hline Interseção & $-0,003853855$ & 0,00654115 & $-0,003853855$ & 0,00654115 \\
Variável X 1 & 1,566232338 & 2,29086505 & 1,566232338 & 2,29086505 \\
\hline
\end{tabular}

Fonte: autores

\section{Eletrobras (elet3)}

A Figura 4 apresenta o resultado anormal da Eletrobrás (ELET3) apurado no dia do evento de 25,010486\%. O mesmo foi dado pelo cálculo comparativo entre o retorno normal, estimativa pelo CAMP de $-9,025616 \%$, e o retorno diário real de $15,984870 \%(15,984870 \%-(9,025616 \%)=25,010486 \%)$. Como nas ações anteriores, procedeu-se para a realização do teste estatístico paramétrico de análise de variância, sendo seus resultados e os resultados da ANOVA apresentados nas Tabelas 13 a 16.

Foi possível apurar que os resultados são significantes com $95 \%$ de confiança ao apresentar que o p-valor ficou maior que o valor do Stat $t$, validando, portanto, a hipótese alternativa de que há diferenças significativas entre o retorno normal e o retorno anormal. Para chegar a tal resultado, aplicou-se o teste "T" para a análise da variância (ANOVA).

Figura 4 - Resultados das janelas do evento da IBOVESPA e da Eletrobrás (ELET3)

\begin{tabular}{|l|l|l|l|l|l|l|}
\hline \multicolumn{1}{|c|}{ Data } & $\begin{array}{c}\text { Fechamento } \\
\text { IBOVESPA }\end{array}$ & $\begin{array}{c}\text { Retorno } \\
\text { Diário Real } \\
\text { IBOVESPA }\end{array}$ & $\begin{array}{c}\text { Fechamento } \\
\text { ELET3 }\end{array}$ & $\begin{array}{c}\text { Retorno } \\
\text { Diário Real } \\
\text { ELET3 }\end{array}$ & $\begin{array}{c}\text { Retorno } \\
\text { Normal } \\
\text { ELET3 }\end{array}$ & $\begin{array}{c}\text { Retorno } \\
\text { Anormal } \\
\text { ELET3 }\end{array}$ \\
\hline $03 / 10 / 2018$ & 83.273 & $2,014943 \%$ & 17,63 & $6,321589 \%$ & $-3,756343 \%$ & $10,077933 \%$ \\
\hline $04 / 10 / 2018$ & 82.953 & $-0,385728 \%$ & 18,50 & $4,816874 \%$ & $0,805432 \%$ & $4,011441 \%$ \\
\hline $05 / 10 / 2018$ & 82.322 & $-0,763934 \%$ & 18,75 & $1,342302 \%$ & $1,516539 \%$ & $-0,174237 \%$ \\
\hline $08 / 10 / 2018$ & 86.084 & $4,469008 \%$ & 22,00 & $15,984870 \%$ & $-9,025616 \%$ & $25,010486 \%$ \\
\hline $09 / 10 / 2018$ & 86.088 & $0,004217 \%$ & 22,81 & $3,615658 \%$ & $0,066594 \%$ & $3,549064 \%$ \\
\hline $10 / 10 / 2018$ & 83.679 & $-2,837532 \%$ & 20,71 & $-9,658236 \%$ & $6,032799 \%$ & $-15,691035 \%$ \\
\hline $11 / 10 / 2018$ & 82.921 & $-0,910017 \%$ & 19,72 & $-4,898333 \%$ & $1,992437 \%$ & $-6,890770 \%$ \\
\hline
\end{tabular}

Fonte: elaborada a partir dos dados obtidos na pesquisa. 
Tabela 13 - Resultados estatísticos da regressão da janela do evento

\begin{tabular}{lc}
\hline & Estatística de regressão \\
\hline R múltiplo & 0,621399296 \\
R-Quadrado & 0,386137085 \\
R-quadrado ajustado & 0,380934857 \\
Erro padrão & 0,034705253 \\
Observações & 120 \\
\hline Fon
\end{tabular}

Fonte: autores

Tabela 14 - Resultados a Anova da janela do evento

\begin{tabular}{llccccc}
\hline & & GI & SQ & MQ & F & F de significação \\
\hline Regressão & 1 & & 0,089401035 & 0,089401035 & 74,22532779 & $3,65042 \mathrm{E}-14$ \\
Resíduo & 118 & & 0,142125638 & 0,001204455 & & \\
Total & 119 & 0,231526673 & & & \\
\hline
\end{tabular}

Fonte: autores

Tabela 15 - Resultados a Anova da janela do evento

\begin{tabular}{lllll}
\hline & \multicolumn{1}{c}{ Coeficientes } & Erro padrão & Stat-t & valor-P \\
\hline Interseção & $-5,62502 \mathrm{E}-05$ & 0,003168287 & $-0,017754141$ & 0,985864974 \\
Variável X 1 & 1,902803141 & 0,220860371 & 8,615412224 & $3,65042 \mathrm{E}-14$ \\
\hline
\end{tabular}

Fonte: autores

Tabela 16 - Resultados a Anova da janela do evento

\begin{tabular}{lllll}
\hline & \multicolumn{1}{c}{$95 \%$ inferiores } & \multicolumn{1}{c}{$95 \%$ superiores } & Inferior $95,0 \%$ & Superior $95,0 \%$ \\
\hline Interseção & $-0,006330322$ & 0,006217822 & $-0,006330322$ & 0,006217822 \\
Variável X 1 & 1,465439477 & 2,340166804 & 1,465439477 & 2,340166804 \\
\hline
\end{tabular}

Fonte: autores

\section{Eletrobras (elet6)}

Percebeu-se, na ação intitulada ELET6 da estatal Eletrobrás que o retorno diário real foi de 16,814219\%, enquanto o retorno normal (CAMP) da mesma foi de $-8,870649 \%$, produzindo um retorno anormal de $25,684867 \%(16,814219 \%-(8,870649 \%)=25,684867 \%)$. Os índices de fechamento, retornos diários reais, retornos normais e retornos anormais, os quais foram utilizados na análise da Eletrobrás (ELET6) para janela do evento, serão apresentados na Figura 5.

A seguir efetuou-se um teste estatístico paramétrico de análise de variância, sendo seus resultados com o intuito de testar o grau de significância examinando os dados por meio do teste "T" para a análise da variância (ANOVA). Tais resultados estão expostos nas Tabelas 17, 18, 19 e 20. Através dos resultados, é possível averiguar que o p-valor ficou consideravelmente maior que o valor do Stat $\mathrm{t}$, revelando que os resultados ao nível de 95\% de confiança são significantes. Isto posto, por meio desses resultados, a hipótese alternativa está validada, confirmando a existência de diferenças significativas entre o retorno normal e o retorno anormal. 
Figura 5 - Resultados das janelas do evento da IBOVESPA e da Eletrobrás (ELET6)

\begin{tabular}{|l|l|l|l|l|l|l|}
\hline \multicolumn{1}{|c|}{ Data } & $\begin{array}{c}\text { Fechamento } \\
\text { IBOVESPA }\end{array}$ & $\begin{array}{c}\text { Retorno } \\
\text { Diário Real } \\
\text { IBOVESPA }\end{array}$ & $\begin{array}{c}\text { Fechamento } \\
\text { ELET6 }\end{array}$ & $\begin{array}{c}\text { Retorno } \\
\text { Diário Real } \\
\text { ELET6 }\end{array}$ & $\begin{array}{c}\text { Retorno } \\
\text { Normal } \\
\text { ELET6 }\end{array}$ & $\begin{array}{c}\text { Retorno } \\
\text { Anormal } \\
\text { ELET6 }\end{array}$ \\
\hline $03 / 10 / 2018$ & 83.273 & $2,014943 \%$ & 21,24 & $8,291091 \%$ & $-3,654977 \%$ & $11,946068 \%$ \\
\hline $04 / 10 / 2018$ & 82.953 & $-0,385728 \%$ & 22,27 & $4,735428 \%$ & $0,781989 \%$ & $3,953440 \%$ \\
\hline $05 / 10 / 2018$ & 82.322 & $-0,763934 \%$ & 22,61 & $1,515181 \%$ & $1,466448 \%$ & $0,048733 \%$ \\
\hline $08 / 10 / 2018$ & 86.084 & $4,469008 \%$ & 26,75 & $16,814219 \%$ & $-8,870649 \%$ & $25,684867 \%$ \\
\hline $09 / 10 / 2018$ & 86.088 & $0,004217 \%$ & 26,79 & $0,149421 \%$ & $0,065681 \%$ & $0,083740 \%$ \\
\hline $10 / 10 / 2018$ & 83.679 & $-2,837532 \%$ & 24,55 & $-8,731683 \%$ & $5,880021 \%$ & $-14,611704 \%$ \\
\hline $11 / 10 / 2018$ & 82.921 & $-0,910017 \%$ & 23,99 & $-2,307478 \%$ & $1,934545 \%$ & $-4,242023 \%$ \\
\hline
\end{tabular}

Fonte: elaborada a partir dos dados obtidos na pesquisa.

Tabela 17 - Resultados estatísticos da regressão da janela do evento

\begin{tabular}{lc}
\hline & Estatística de regressão \\
\hline R múltiplo & 0,610261205 \\
R-Quadrado & 0,372418738 \\
R-quadrado ajustado & 0,367100253 \\
Erro padrão & 0,03465855 \\
Observações & 120 \\
\hline
\end{tabular}

Fonte: autores

Tabela 18 - Resultados a Anova da janela do evento

\begin{tabular}{|c|c|c|c|c|c|}
\hline & GI & SQ & MQ & $\mathrm{F}$ & F de significação \\
\hline Regressão & 1 & 0,084113237 & 0,084113237 & 70,02345962 & 1,36833E-13 \\
\hline Resíduo & 118 & 0,141743382 & 0,001201215 & & \\
\hline Total & 119 & 0,22585662 & & & \\
\hline
\end{tabular}

Fonte: autores

Tabela 19 - Resultados a Anova da janela do evento

\begin{tabular}{llccc}
\hline & \multicolumn{1}{c}{ Coeficientes } & \multicolumn{1}{c}{ Erro padrão } & Stat-t & valor-P \\
Interseção & $-3,64339 \mathrm{E}-05$ & 0,003164024 & $-0,011515053$ & 0,990831966 \\
Variável X 1 & 1,845673009 & 0,220563162 & 8,368002128 & $1,36833 \mathrm{E}-13$ \\
\hline
\end{tabular}

Fonte: autores

Tabela 20 - Resultados a Anova da janela do evento

\begin{tabular}{lllll}
\hline & \multicolumn{1}{c}{$95 \%$ inferiores } & \multicolumn{1}{c}{$95 \%$ superiores } & \multicolumn{1}{c}{ Inferior 95,0\% } & \multicolumn{1}{c}{ Superior 95,0\% } \\
\hline Interseção & $-0,006302063$ & 0,006229195 & $-0,006302063$ & 0,006229195 \\
Variável X 1 & 1,4088979 & 2,282448118 & 1,4088979 & 2,282448118 \\
\hline
\end{tabular}

Fonte: autores

\section{Considerações finais}

O mercado de capitais no Brasil é caracterizado pela presença de uma elevada quantidade de empresas de controle estatal federal e até mesmo estadual, possuindo expressivo volume de negociação nos pregões diários da B3. A estrutura de governança das empresas estatais brasileiras são sensíveis às mudanças alterações na estrutura de poder executivo federal e estadual, na medida em que cabe ao poder executivo e seus ministros a nomeação dos presidentes e diretores das estatais. 
Os candidatos que disputaram o último pleito eleitoral para presidente da república apresentavam propostas distintas em relação ao papel das empresas estatais, onde o então candidato Jair Bolssonaro prometia a modernização e profissionalização da gestão, incluindo um amplo programa de desestatização, visando reduzir o papel de empresário do estado brasileiro.

Considerando que o Estudo de Eventos é um método utilizado para mensurar o impacto de eventos corporativos no valor da firma através do cálculo de retornos anormais, ou seja, a diferença entre o retorno real de um título com o seu retorno esperado, estimado a partir da modelagem econométrica, neste caso foi utilizado o Capital Asset Princing Model (CAPM).

Este trabalho objetivou analisar, através de um estudo de eventos e a utilização do teste T de Student, os impactos causados nas cotações das ações das empresas estatais federais de capital aberto listadas na B3 pelo resultado do primeiro turno da eleição do Presidente Jair Messias Bolsonaro.

É interessante notar que, ao realizar tal análise, pôde-se constatar a velocidade, eficácia e eficiência dessas sociedades públicas mistas em absorver a informação da mudança estrutural do próprio governo e a forma como é passada para o preço de suas ações na B3, dado pelas expectativas dos investidores e dos demais agentes econômicos quanto à valoração da empresa ou de todo seu mercado em relação ao evento. Isso pode ser apresentado não somente pelo retorno anormal, mas também pela observação do retorno no período posterior ao evento que demonstra a assimilação das informações postas no mercado e a colocação do valor do preço das ações modificado por essa informação.

Com esse estudo, constatou-se, portanto, que o mercado de capitais brasileiro, pelo menos no que diz respeito a esse evento e para essas empresas estatais analisadas, teve reação positiva. Dessa forma, os retornos anormais de todas as ações demonstraram-se significantes com $95 \%$ de confiança, validando, portanto, a hipótese alternativa, isto é, há diferenças significativas entre o retorno normal e o retorno anormal. Verificou-se, através de testes estatísticos, que não houve afetações consistentes nos desempenhos das ações no período.

O presente estudo apresentou importantes indícios, representados pelos anormais nos preços das ações das empresas públicas federais, que os investidores reagem e expõem suas expectativas por meio dos preços das ações à sinalização de possíveis mudanças, não só nas políticas econômicas a serem exercidas pelo estado, mas também sobre as políticas públicas e da estrutura do governo brasileiro. Entende-se que há espaço para a interpretação das empresas ligadas diretamente ao estado, como as estatais (principalmente as federais, que são parcialmente controladas pela União) tendem a ter relações mais significativas com a correlação entre a mudança dos preços das suas ações e o evento das eleições presidenciais.

Além disso, ao se analisar os resultados alcançados e levando em conta a comparação entre os resultados apresentados em cada empresa, juntamente com a concepção que essas empresas em sua maioria são representantes da economia brasileira no mercado que atuam e no mercado de capitais, pode-se observar que o Banco do Brasil e a Petrobrás, empresas com mais força em seus mercados e com melhores desempenhos, tiveram retornos anormais menos relevantes do que comparado com a Eletrobras, que teve grande prejuízo no ano analisado, o que infere uma melhor interpretação das informações dispostas tanto no período dos resultados das eleições quanto no período da campanha eleitoral, o qual já demonstra expectativas e anseios da população.

Para estudos futuros, recomenda-se que a análise compreenda um espaço temporal maior para a janela de evento e a de observação do estudo, podendo ainda envolver o acontecimento de eleições presidenciais em outros países com os quais as empresas estatais mantenham forte ligação econômica. Outrora, sugere-se utilizar outras empresas estatais que tenham suas ações negociadas na B3 e que não estejam no âmbito federal. A partir disso, por exemplo, poder-se-ia utilizar empresas estatais estaduais empregando como evento as eleições para deputados e governadores estaduais. 


\section{Referências}

Ashley, J. W. (1962). Stock prices and changes in earnings and dividends: some empirical results. Journal of Political Economy, 70(1), 82-85.

Assaf Neto, A. (2014). Mercado Financeiro. 12. ed. São Paulo: Atlas.

B3 - Brasil Bolsa Balcão (2018). B3 registra recorde no total geral de negócios nos segmentos BM \& F e Bovespa. Recuperado em 30 de abril de 2020, de http://www.b3.com.br/pt br/noticias/recordes8AA8D0CD66BFABD40166C208167E1A86.htm

Ball, R., \& Brown, P. (1968). An empirical evaluation of accounting income numbers. Journal of accounting research, 159-178.

Baltar, P. E. A. (2016). Estagnação da economia, abertura e crise do emprego urbano no Brasil. Economia e Sociedade, 5(1), 75-111.

Barker, C. A. (1956). Effective stock splits. Harvard Business Review, 34(1), 101-106.

Barker, C. A. (1957). Stock splits in a bull market. Harvard Business Review, Harvard University, 34(3), $72-$ 79 .

Bergmann, D. R., Savoia, J. R. F., Souza, B. D. M., \& Mariz, F. D. (2015). Avaliação dos Processos de Fusões e Aquisições no setor Bancário Brasileiro por meio de Estudo de Eventos. Revista Brasileira de Gestão de Negócios, 17(56), 1105-1115.

Bresser-Pereira, L. C. (2010). A macroeconomia estruturalista do desenvolvimento por trás do novo desenvolvimentismo. Revista de la Cepal, n.100.

Brown, S. J., Warner, J. B. (1980). Measuring security price performance. Journal of Financial Economics, Amsterdam: North Holland, 8(3), 205-258.

Brown, S. J., \& Warner, J. B. (1985). Using daily stock returns: The case of event studies. Journal of financial economics, 14(1), 3-31.

Cacciamali, M. C. (2016). Globalização e processo de informalidade. Economia e sociedade, 9(1), 153-174.

Camargos, M. A. D., \& Barbosa, F. V. (2010). Estudos de Evento: teoria e operacionalização. REGE Revista de Gestão, 10(3).

Campbell, J. Y., Champbell, J. J., Campbell, J. W., Lo, A. W., Lo, A. W., \& MacKinlay, A. C. (1997). The econometrics of financial markets. Princeton University Press.

Getz, D.(2012). Event studies: Theory, research and policy for planned events. Routledge.

DeMiguel, V., Nogales, F. J., \& Uppal, R. (2014). Stock return serial dependence and out-of-sample portfolio performance. The Review of Financial Studies, 27(4), 1031-1073.

Dolley, J. C. (1933). Characteristics and procedure of common stock split-ups. Harvard Business Review, 11(3), 316-326.

Duch, R. M., \& Stevenson, R. T. (2008). The economic vote: How political and economic institutions condition election results. Cambridge University Press.

Dutra, P. P. D. A. (1991). Controle de empresas estatais: uma proposta de mudança. Editora Saraiva.

Elbannan, M. A. (2015). The capital asset pricing model: an overview of the theory. International Journal of Economics and Finance, 7(1), 216-228.

Exame (2018a). BM \& FBovespa registra recordes de negócios. Recuperado em 30 de abril de 2020, de https://exame.abril.com.br/mercados/bm-fbovespa-registra-recordes-de-negocios/. 
Fama, E. F., Fisher, L., Jensen, M. C., \& Roll, R. (1969). The adjustment of stock prices to new information. International economic review, 10(1), 1-21.

Folha de São Paulo (2018b). Bolsa tem recorde de negociações e sobe 4\% após $1^{\circ}$ turno com vantagem de Bolsonaro. Recuperado em 30 de abril de: https://www1.folha.uol.com.br/mercado/2018/10/bolsa-fecha-em-altade-mais-de-4-apos-1o-turno-mostrar-ampla-vantagem-de-bolsonaro.shtml

Folha de São Paulo (2018c). Desde 1989, Brasil nunca teve virada no segundo turno da eleição presidencial. Recuperado em 30 de abril de: https://www1.folha.uol.com.br/poder/2018/10/desde-diretas-ja-brasilnunca-teve-virada-no-segundo-turno-da-eleicao-presidencial.shtml

Fortuna, E. (2010). Mercado financeiro: produtos e serviços. rev. e atual. Rio de Janeiro: Qualitymark.

Gaddis, G. M., \& Gaddis, M. L. (1990). Introduction to biostatistics: Part 4, statistical inference techniques in hypothesis testing. Annals of emergency medicine, 19(7), 820-825.

Gobetti, S. W. (2010). Estatais e ajuste fiscal: uma análise da contribuição das empresas federais para o equilíbrio macroeconômico. Economia e Sociedade, 19(1), 29-58.

Goes, J. S. (2015). Fusão Sadia/Perdigão: Análise do caso sob a metodologia de estudos de eventos. Tese de Doutoramento, Universidade Federal do Ceará.

Junior, M. P. L., \& Carvalho, V. G. (2015). Impacto ambiental e retorno acionário de companhias listadas na bm\&fbovespa. EmpiricaBR-Revista Brasileira de Gestão, Negócio e Tecnologia da Informação, 1(1), 43-54.

Kan, R., Robotti, C., \& Shanken, J. (2013). Pricing model performance and the two-pass cross-sectional regression methodology. The Journal of Finance, 68(6), 2617-2649.

Lintner, J. (1975). The valuation of risk assets and the selection of risky investments in stock portfolios and capital budgets. In Stochastic optimization models in finance (pp. 131-155). Academic Press.

Lopes, J. D. C., \& Rossetti, J. P. (1988). Economia monetária. 7 ed. São Paulo: Atlas.

Martins, J. P. C. B. (2014). As interações entre a política monetária e o mercado de capitais. Universidade federal de Santa Catarina.

Mattoso, J. (1998). Mudanças estruturais e trabalho no Brasil. Economia e Sociedade, 7(1), 213-243.

McWilliams, A., \& Siegel, D. (1997). Event studies in management research: Theoretical and empirical issues. Academy of management journal, 40(3), 626-657.

Mishkin, F., Mishkin, F. S., \& Mishkin, F. (2000). Moedas, bancos e mercados financeiros. 5.ed. Rio de Janeiro: LTC

Mossin, J. (1966). Equilibrium in a capital asset market. Econometrica: Journal of the econometric society, 768783.

Myers, J. H., \& Bakay, A. J. (1948). Influence of stock split-ups on market price. Harvard Business Review, 26(2), 251-255.

Neves, M. P. D. (2007). Investimento em mercado de capitais: estudo do equilibrio entre riscos e retorno, através da diversificação eficiente. Universidade Federal do Rio Grande do Sul.

Oliveira, G. A., \& Pacheco, M. (2006). Mercado financeiro: objetivo e profissional. São Paulo: Fundamentos.

Peixoto, V., \& Rennó, L. (2011). Mobilidade social ascendente e voto: as eleições presidenciais de 2010 no Brasil. Opinião Pública, 17(2), 304-332.

Pereira, M. A., Securato, J. R., \& de Sousa, A. F. (2016). Efeito dos investimentos nos fundamentos e na reação de mercado de empresas brasileiras pré-operacionais e operacionais do período de 2006 a 2012. Revista de Administração, 51(1), 56-71. 
Pessanha, G. R. G., Santos, T. A. D., Calegario, C. L. L., Sáfadi, T., \& Alcântara, J. N. D. (2014). Influências das fusões e aquisições no valor de mercado das instituições bancárias adquirentes. Contabilidade, Gestão e Governança, 17(3).

Pinheiro, J. L. (2001). Mercado de capitais: fundamentos e técnicas. 5. ed. São Paulo: Atlas.

Pinto Junior, M. E. (2000). Empresa Estatal: Função Econômica E Dilemas Societários. São Paulo: Atlas.

Polinsky, A. M., \& Shavell, S. (Eds.). (2007). Handbook of law and economics. New York: Elsevier.

Prechter Jr, R. R., Goel, D., Parker, W. D., \& Lampert, M. (2012). Social mood, stock market performance, and US presidential elections: A socionomic perspective on voting results. SAGE Open, 2(4).

Ribeiro, M. C. P., Alves, R. D. S., \& Chede, G. D. (2009). Gestão das empresas estatais: uma abordagem dos mecanismos societários e contratuais. BRASIL. Ministério do Planejamento, orçamento e Gestão, Secretaria Executiva, Departamento de Coordenação e Governança das Empresas Estatais. Prêmio Dest. Monografias: empresas estatais: monografias premiadas, 2008.

Ross, S. A. (1976). The arbitrage theory of capital asset pricing, 'Journal of Economic Theory'. 13(3), 341-360.

Secchi, L. (2012). Politicas públicas: conceitos, esquemas de análise, casos práticos. São Paulo: Cengage Learning. Sharpe, W. F. (1964). Capital asset prices: A theory of market equilibrium under conditions of risk. The journal of finance, 19(3), 425-442.

Sharpe, W. F. (1970). Portfolio theory and capital markets. McGraw-Hill College.

Sharpe, W. F., Alexander, G. J., \& Bailey, J. (1995). Investments prentice hall. Englewood Cliffs, New Jersey, 7632.

Silva, A. da, Barbosa, J., \& Ribeiro, F. (2017). Comportamento do Volume de Negociações e do Risco de Mercado antes e após os Resultados das Eleições Presidenciais em 2014: Um Estudo com Empresas Brasileiras de Capital Aberto. Revista Evidenciação Contábil \& Finanças, 5(1), 39-55.

Souza, C. (2007). Estado da arte da pesquisa em políticas públicas. Políticas públicas no Brasil. Rio de Janeiro: Fiocruz, 65-86.

Tácito, C. (2005). Regime jurídico das empresas estatais. Revista de Direito Administrativo, 245, 85-93.

Tinbergen, J. (1986). Política econômica: princípios e planejamento. São Paulo: Nova Cultural.

Vieira, K. M. \& Pracianoy, J. L. (2001). Reação dos investidores a bonificações: um estudo em países da América Latina. XXV ENANPAD. Anais... Campinas: ANPAD.

Vieira, K. M., \& Procianoy, J. L. (2003). Reação dos investidores a bonificações e desdobramentos: o caso brasileiro. Revista de Administração Contemporânea, 7(2), 9-33.

Zabarankin, M., Pavlikov, K., \& Uryasev, S. (2014). Capital asset pricing model (CAPM) with drawdown measure. European Journal of Operational Research, 234(2), 508-517. 